\title{
ABBREVIATIONS
}

\section{AASS-Acta Sanctorum}

ASSOB - Acta Sanctorum ordinis S. Benedicti

Archiv—Archiv der Gesellschaft für ältere deutsche Geschichtskunde

BEDC-Bibliothèque de l'Ecole des Chartes

ChLA-Chartae Latinae Antiquiores

CLA-Codices Latini Antiquiores

DA-Deutsches Archiv für Erforschung des Mittelalters

MGH, Dipl.-Monumental Germaniae Historica, Diplomata Imperii

MGH, Epistolae—Monumenta Germaniae Historica, Epistolae

MGH, Leges-Monumenta Germaniae Historica, Leges

MGH, SS-Monumenta Germaniae Historica, Scriptores

MGH, SSRG-Monumenta Germaniae Historica, Scriptores Rerum

Germanicarum in usum scholarum

MGH, SSRM-Monumenta Germaniae Historica, Scriptores Rerum

Merovingicarum

MGH SSRL_Monumenta Germaniae Historica, Scriptores Rerum

Langobardicum et Italicarum

MIÖG-Mitteilungen de Instituts für österreichische Geschichtsforschung

NA-Neues Archiv der Gesellschaft für ältere deutsche Geschichtskunde

PL-Patrologica Latina

Settimane di Studio-Settimane di Studio del Centro Italiano di Studi sull'alto

Medioevo (Spoleto) 
Paul Fouracre and Richard A. Gerberding - 9781526112781 Downloaded from manchesterhive.com at 04/26/2023 04:44:13AM 